\title{
Universal Design Tactile Graphics Production System BPLOT4 for Blind Teachers and Blind Staffs to Produce Tactile Graphics and Ink Print Graphics of High Quality
}

\author{
Mamoru Fujiyoshi ${ }^{1}$, Akio Fujiyoshi $\left.^{2(}{ }^{(}\right)$, Hiroshi Tanaka ${ }^{3}$, and Toru Ishida ${ }^{4}$ \\ 1 National Center for University Entrance Examinations, Meguro, Tokyo, Japan \\ fujiyosi@rd.dnc.ac.jp \\ 2 Ibaraki University, Hitachi, Ibaraki, Japan \\ akio.fujiyoshi.cs@vc.ibaraki.ac.jp \\ 3 Tsukuba University of Technology, Tsukuba, Ibaraki, Japan \\ htanaka@k.tsukuba-tech.ac.jp \\ 4 National Rehabilitation Center For Persons with Disabilities, \\ Tokorozawa, Saitama, Japan \\ ishidat@oas.nvrc-unet.ocn.ne.jp
}

\begin{abstract}
In order to extend the usability of BPLOT, a new version BPLOT4 was developed. BPLOT is the first tactile graphics production system for the blind that enables the blind to produce tactile graphics by themselves. BPLOT4 has obtained the following four new features: (1) The usage of variables and mathematical formulas is supported for the description of plotter control commands. (2) The production of ink print graphics is possible at the same time as that of tactile graphics.

(3) A new GUI (Graphical User Interface) is developed for sighted users.

(4) Everest-D V5 (Index Braille) is added to the list of supported Braille printers.
\end{abstract}

Keywords: Blind $\cdot$ Tactile graphics $\cdot$ Universal design

Plotter control language · User interface

\section{Introduction}

This paper introduces the newly updated universal design tactile graphics production system BPLOT4. BPLOT is the first tactile graphics production system for the blind that enables the blind to produce tactile graphics by themselves [1-3]. Existing tactile graphics design applications such as BES [4] and EDEL-plus [5] have sophisticated GUI (Graphical User Interface) and enable the sighted to produce tactile graphics easily. However, because of the necessity for mouse operations, the blind cannot use these applications by themselves. Tiger Software Suite [6] can create tactile graphics by translating graphics on

(c) The Author(s) 2018

K. Miesenberger and G. Kouroupetroglou (Eds.): ICCHP 2018, LNCS 10897, pp. 167-176, 2018.

https://doi.org/10.1007/978-3-319-94274-2_23 
computer screen into tactile graphics automatically. Both the blind and the sighted can use it. However, it is not enough for the blind to produce elaborate tactile graphics for figures in textbooks or questions of entrance examinations. BPLOT produces tactile graphics from a source text file written in our specially designed plotter control language for BPLOT. Because a source file for BPLOT is a text file, it is editable with any text editors by any person who has learned the plotter control language. Therefore, BPLOT enables not only the sighted but also the blind to produce tactile graphics by themselves.

The first version of BPLOT was developed in 2004. It was only with CUI (Character User Interface) and not WYSIWYG (What You See Is What You Get). In 2007, GUI for BPLOT was developed, and BPLOT2 was introduced [1]. With GUI, the usability of BPLOT2 for the sighted was significantly improved because a sighted user does not need a detailed knowledge of the plotter control language. A synchronized mechanism between CUI and GUI was developed, and BPLOT3 was introduced [3]. With the synchronized CUI and GUI, the blind and the sighted can collaboratively produce tactile graphics.

In order to extend the usability of BPLOT, a new version BPLOT4 was developed. BPLOT4 has obtained the following four new features: (1) The usage of variables and mathematical formulas is supported for the description of plotter control commands. (2) The production of ink print graphics is possible at the same time as that of tactile graphics. (3) A new GUI (Graphical User Interface) is developed for sighted users. (4) Everest-D V5 (Index Braille) is added to the list of supported Braille printers.

\section{Outline and New Features of BPLOT4}

\subsection{The System}

BPLOT4 runs on Microsoft Windows 7, 8 or 10. The main program of BPLOT4 is written in $\mathrm{C}++$, and the user interface part is written in $\mathrm{C \# \text {. }}$

It works with the Braille printer ESA721, ESA600G (JTR Corporation) and Everest-D V5 (Index Braille). In order to obtain tactile graphics of high quality, we chose ESA721, ESA600G and Everest-D V5. They can produce tactile graphics with very high resolution: $73 \mathrm{dpi}$ (dot/inch) for ESA721, $100 \mathrm{dpi}$ for ESA600G, and 50 dpi for Everest-D V5. The resolution of ordinary Braille printers is only $10-20 \mathrm{dpi}$.

\subsection{Plotter Control Language}

In order to design tactile graphics by text editors, a plotter control language was developed [1]. The plotter control language is like a computer programming language which consists of plotter control commands. Each command consists of a command name and parameters. Basic figures such as a circle, a straight line, a rectangle, a diamond shape and several kinds of arrows can be described by a single command. 


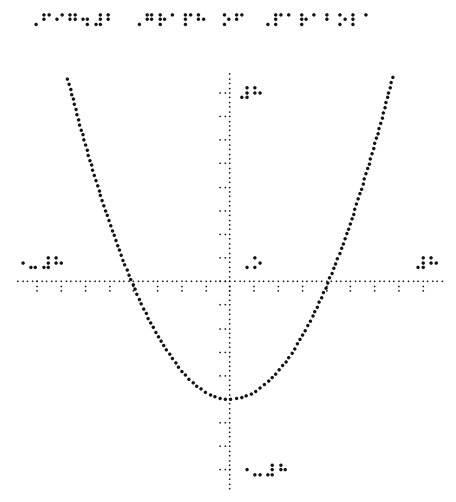

Fig. 1. An example of tactile graphics produced by BPLOT

For figures frequently used, we prepared commands to describe those figures in one line. A parabola, a hyperbola, a trigonometric function, an exponential function and a logarithmic function can be described by a single command. In plotting graphs, the axis of coordinates can also be described by a single command. For example, the horizontal axis, the vertical axis and the parabolic curve in Fig. 1 are described by the following three commands in the plotter control language.

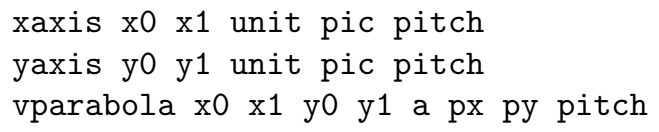

xaxis and yaxis are command names to draw a horizontal axis and a vertical axis, respectively. The parameters $\mathrm{x} 0$ and $\mathrm{x} 1$ ( $\mathrm{y} 0$ and $\mathrm{y} 1$ ) specify the range of an axis, unit means the intervals of divisions, pic indicates the length of divisions, and pitch sets the pitch of a dotted line. Likewise, vparabola is a command name to draw a vertical parabolic curve. The parameters $\mathrm{x} 0, \mathrm{x} 1, \mathrm{y} 0$ and $\mathrm{y} 1$ specify the range of a curve, a, px and py indicate the parameters of a vertical parabolic curve $y=a(x-p x)^{2}+p y$, and pitch sets the pitch of a dotted line.

Graphs including complicated curves can be described by means of spline functions. To import a series of plotter control commands written in another file, we use the "paste" command. To put a Braille caption in a figure, we use the "braille" command. NABCC (North American Braille Computer Code) and Japanese KANA code are supported.

We also have commands to define the virtual coordinate space on a sheet of paper. With them, we can magnify and reduce the output tactile graphics with the same sense of touch because lines are drawn with the same dot pitch. 


\subsection{New Features of BPLOT4}

\section{(1) Usage of Variables and Mathematical Formulas in Plotter Control Commands}

Since the usage of variables and mathematical formulas is supported for the description of plotter control commands in BPLOT4, the calculations of parameters of commands can be done automatically. When a user wants to modify the location or shape of a figure, it can be done by changing the assigned values of variables. As for the previous version of BPLOT, the parameters of a command were only numerical values, and thus those values have to be calculated in advance to write a command. Moreover, to modify the location or shape of a figure, all parameters concerning the figure have to be re-calculated by hand.

For mathematical formulas, we can use the four operators $(+, I, *$ and $/)$ and many important functions $(\operatorname{sqrt}(x), \sin (x), \cos (x), \tan (x), \exp (x), \log (x)$ and $\log 10(\mathrm{x}))$.

Figure 2 is a figure-drawing program describing a star-shaped curve. The produced tactile graphics is shown in Fig. 3. In Fig. 2, 1, m, r, pitch, x0, .., x10, and $\mathrm{y} 0, \ldots, \mathrm{y} 10$ are variables. The size of figure can be adjusted with the variables 1 and $\mathrm{m}$.

\begin{tabular}{|c|c|c|c|}
\hline 1 & $1=6$ & 24 & $\mathrm{x} 9=\mathrm{m} * \cos (90+9 * r)$ \\
\hline 2 & $\mathrm{~m}=4$ & 25 & $\mathrm{y} 9=\mathrm{m} * \sin (90+9 * r)$ \\
\hline 3 & $r=360 / 10$ & 26 & $\mathrm{x} 10=1 * \cos (90+10 * r)$ \\
\hline 4 & pitch $=2.2$ & 27 & $\mathrm{y} 10=1 * \sin (90+10 * r)$ \\
\hline 5 & & 28 & \\
\hline 6 & $\mathrm{x} 0=1 * \cos (90+0 * r)$ & 29 & define range $\begin{array}{lllll}-10 & 10 & -12 & 12\end{array}$ \\
\hline 7 & $\mathrm{y} 0=1 * \sin (90+0 * r)$ & 30 & define EndofData 99990 \\
\hline 8 & $\mathrm{x} 1=\mathrm{m} * \cos (90+1 * \mathrm{r})$ & 31 & func $=4$ \\
\hline 9 & $\mathrm{y} 1=\mathrm{m} * \sin (90+1 * r)$ & 32 & \\
\hline 10 & $\mathrm{x} 2=1 * \cos (90+2 * r)$ & 33 & $\operatorname{dot} 1$ \\
\hline 11 & $\mathrm{y} 2=1 * \sin (90+2 * r)$ & 34 & spline range func 00 pitch \\
\hline 12 & $\mathrm{x} 3=\mathrm{m} * \cos (90+3 * r)$ & 35 & $\mathrm{x} 0 \mathrm{y} 0$ \\
\hline 13 & $\mathrm{y} 3=\mathrm{m} * \sin (90+3 * r)$ & 36 & $\mathrm{x} 1 \mathrm{y} 1$ \\
\hline 14 & $x 4=1 * \cos (90+4 * r)$ & 37 & $\mathrm{x} 2 \mathrm{y} 2$ \\
\hline 15 & $\mathrm{y} 4=1 * \sin (90+4 * r)$ & 38 & $\mathrm{x} 3$ y3 \\
\hline 16 & $\mathrm{x} 5=\mathrm{m} * \cos (90+5 * r)$ & 39 & $\mathrm{x} 4 \mathrm{y} 4$ \\
\hline 17 & $\mathrm{y} 5=\mathrm{m} * \sin (90+5 * \mathrm{r})$ & 40 & $\mathrm{x} 5 \mathrm{y} 5$ \\
\hline 18 & $x 6=1 * \cos (90+6 * r)$ & 41 & $\mathrm{x} 6 \mathrm{y} 6$ \\
\hline 19 & $y 6=1 * \sin (90+6 * r)$ & 42 & $\mathrm{x} 7 \mathrm{y} 7$ \\
\hline 20 & $\mathrm{x} 7=\mathrm{m} * \cos (90+7 * \mathrm{r})$ & 43 & $\mathrm{x} 8 \mathrm{y} 8$ \\
\hline 21 & $\mathrm{y} 7=\mathrm{m} * \sin (90+7 * r)$ & 44 & x9 y9 \\
\hline 22 & $\mathrm{x} 8=1 * \cos (90+8 * r)$ & 45 & EndofData \\
\hline 23 & $y 8=1 * \sin (90+8 * r)$ & & \\
\hline
\end{tabular}

Fig. 2. A figure-drawing program for star-shaped curve 


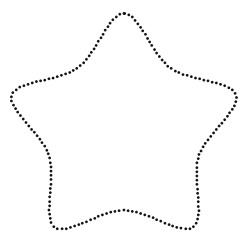

Fig. 3. The tactile graphics described by the program in Fig. 2

\section{(2) Production of Ink Print Graphics}

We developed a converter for BPLOT that translates the plotter control language into PostScript. PostScript [7], created by Adobe Systems, is a page description language widely used to describe documents including ink print figures and pictures. Since the plotter control language of BPLOT has many parts in common with PostScript, this conversion is straightforward. With this function, blind teachers and blind staffs can make ink print graphics of high quality for sighted students. Figure 4 shows the ink print graphics obtained from the program in Fig. 2.

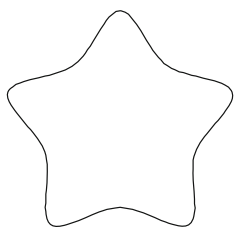

Fig. 4. The ink print graphics obtained from the program in Fig. 2

\section{(3) New GUI for Sighted Users}

For sighted users, a new GUI (Graphical User Interface) was developed, and the usability improved. Tactile graphics can be edited with simple operations. See Fig. 5.
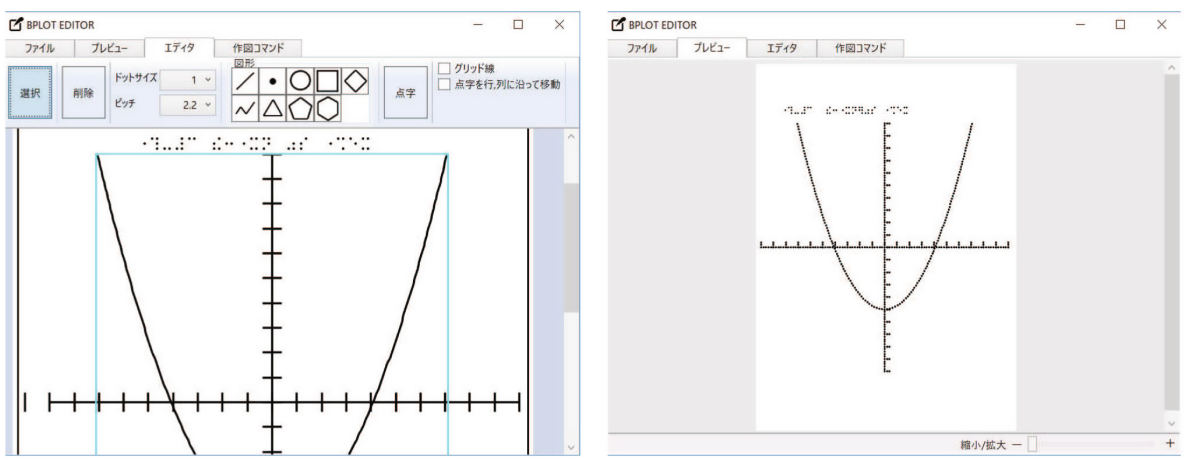

Fig. 5. Edit screen and preview screen of the GUI 


\section{(4) Everest-D V5 (Index Braille) Supported}

Since it is not difficult for BPLOT to support new Braille printers, the new version can control Everest-D V5. We plans to support other Braille printers if requested.

\section{Experimental Evaluation}

For the evaluation, two experiments were conducted. The first experiment is to compare time needed to produce tactile graphics for blind persons with BPLOT and sighted persons with a tactile graphics editor. The second experiment is to evaluate the quality of products made by a blind person using BPLOT.

\subsection{Comparison of Time Needed to Produce Tactile Graphics}

The purpose of this experiment is to compare time needed to produce tactile graphics for blind persons by writing plotter control commands of BPLOT and sighted persons by using the tactile graphics editor EDEL-plus [5].

Method: The blind subjects are two blind men (age 60s and 70s) who are familiar with using BPLOT, and the sighted subjects are two women (age 40s and 60s) who are Braille transcribers. The assignments are to draw the four basic tactile graphics shown in Fig. 6. The blind subjects are given them as a document, while the sighted subjects are given as a set of pictures. The blind subjects are allowed to print out uncompleted products and check them tactually several times before the completions.

Result: The quality of products made by all the four subjects is good enough for teaching materials. Figure 6 shows the products made by one of the blind subjects.

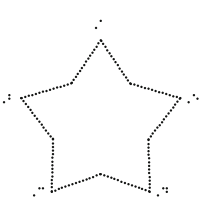

(1)

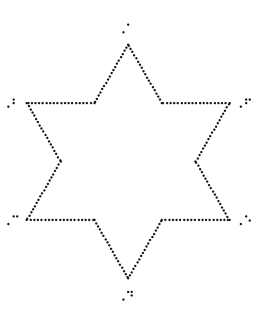

(2)

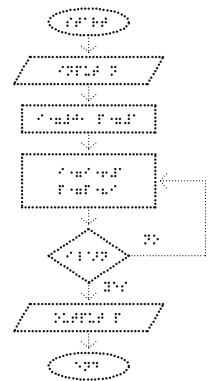

(3)

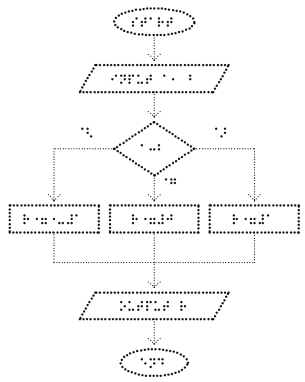

(4)

Fig. 6. Tactile graphics made by one of the blind subjects from the assignments 
The time needed to produce tactile graphics for the blind subjects are (1) $46.5 \mathrm{~s},(2) 71.0 \mathrm{~s},(3) 127.5 \mathrm{~s}$, and (4) $103.0 \mathrm{~s}$ on average. The time needed for the sighted subjects are (1) $22.5 \mathrm{~s}$, (2) $9.0 \mathrm{~s}$, (3) $47.0 \mathrm{~s}$, and (4) $36.5 \mathrm{~s}$ on average. For (1), (3) and (4), the blind subjects take from 2.1 times to 2.8 times longer than the sighted subjects. However, for (2), the blind subjects take 7.9 times longer than the sighted subjects. This difference may be because the blind subjects had to calculate the coordinates of intersection points, while the sighted subjects can draw two regular triangles and erase dots in the inner part.

\subsection{Evaluation of the Quality of Products Made Using BPLOT}

The purpose of this experiment is to evaluate the quality of products made by a blind person using BPLOT. Not only tactile graphics but also ink print graphics are evaluated whether they have enough quality for teaching materials.

Method: All the subjects are teachers in a school for the blind. The blind subjects are eight blind teachers, and the sighted subjects are eight sighted teachers. The assignments are to evaluate the quality of tactile graphics and ink print graphics converted from the tactile graphics. There are the four types of tactile graphics and ink print graphics shown in Fig. 7: (A1), (B1) Distribution graph, (A2), (B2) Trigonometric function graph, (A3), (B3) Symbol mark, and (A4), (B4) Box-and-whisker plot.

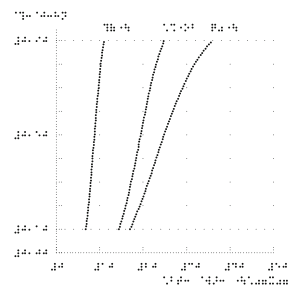

(A1)

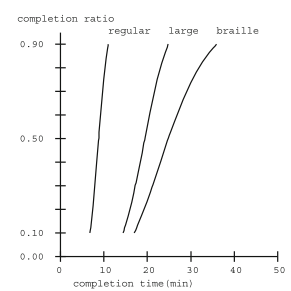

(B1)

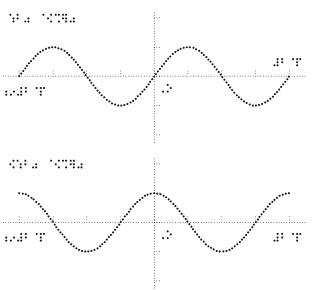

(A2)

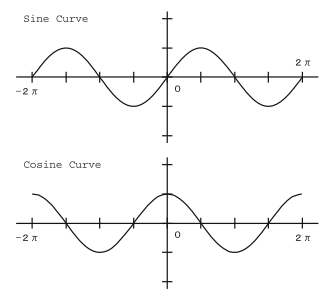

(B2)

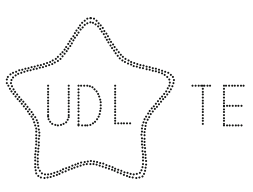

(A3)

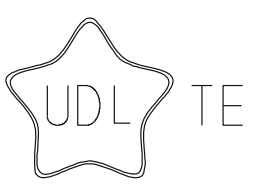

(B3)

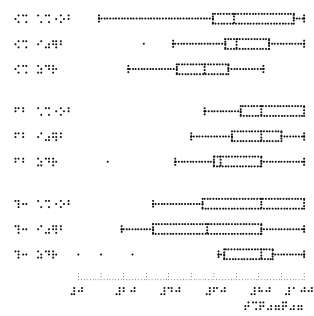

(A4)

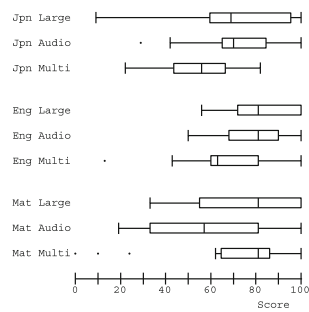

(B4)

Fig. 7. Tactile graphics and ink print graphics converted from the tactile graphics made by a blind person using BPLOT 
The blind subjects are asked to evaluate only tactile graphics, and the sighted subjects are asked to evaluate both tactile graphics and ink print graphics. Ratings for the evaluation are chosen from the following 7 values: Very good (3 points), Good (2 points), Slightly good (1 point), Neutral (0 point), Slightly poor ( -1 point), Poor ( -2 points), and Very poor ( -3 points).

Result: The averages of ratings for the assignments are presented in Table 1. As a result of the evaluation, the quality of tactile graphics made by a blind person using BPLOT is mostly good enough for teaching materials, and ink print graphics converted from the tactile graphics are mostly acceptable for teaching materials for sighted students. However, the ratings by the sighted subjects for box-and-whisker plot are not good. As tactile proofreading by a blind person is necessary for the production of tactile graphics, the production of ink print graphics by the blind might need proofreading by a sighted person.

Table 1. The averages of ratings for the assignments $(n=16)$

\begin{tabular}{l|l|l|l|l|l|l}
\hline Group & Media & (A1), (B1) & (A2), (B2) & (A3), (B3) & (A4), (B4) & Average \\
\hline Blind & Tactile & 1.69 & 1.44 & 0.81 & 0.50 & 1.11 \\
Sighted & Tactile & 0.63 & 1.00 & 1.12 & -0.25 & 0.62 \\
Sighted & Ink print & 0.50 & 1.00 & 0.75 & -0.25 & 0.50 \\
\hline
\end{tabular}

\section{Conclusion}

BPLOT4 enables blind teachers and blind staffs in schools and libraries to make tactile graphics and ink print graphics of high quality. The blind can use it by themselves. We expect that employment opportunities for the blind will be expanded. BPLOT4 and its manual with many samples are available on the following web site: http://apricot.cis.ibaraki.ac.jp/BPLOT/.

Acknowledgement. This work was supported by grants for social welfare activities from the Mitsubishi Foundation.

\section{References}

1. Fujiyoshi, M., Fujiyoshi, A., Ohtake, N., Yamaguchi, K., Teshima, Y.: The development of a universal design tactile graphics production system BPLOT2. In: Miesenberger, K., Klaus, J., Zagler, W., Karshmer, A. (eds.) ICCHP 2008. LNCS, vol. 5105, pp. 938-945. Springer, Heidelberg (2008). https://doi.org/10.1007/978-3-54070540-6_141 
2. Fujiyoshi, M., Kaneko, T., Fujiyoshi, A., Oouchi, S., Yamazawa, K., Ikegami, Y., Watanabe, Y., Teshima, Y.: Development of tactile graphics production software for three-dimensional projections. In: Miesenberger, K., Klaus, J., Zagler, W., Karshmer, A. (eds.) ICCHP 2010. LNCS, vol. 6180, pp. 541-547. Springer, Heidelberg (2010). https://doi.org/10.1007/978-3-642-14100-3_81

3. Fujiyoshi, M., Fujiyoshi, A., Osawa, A., Kuroda, Y., Sasaki, Y.: Development of synchronized CUI and GUI for Universal design tactile graphics production system BPLOT3. In: Miesenberger, K., Fels, D., Archambault, D., Peňáz, P., Zagler, W. (eds.) ICCHP 2014. LNCS, vol. 8548, pp. 18-25. Springer, Cham (2014). https:// doi.org/10.1007/978-3-319-08599-9_4

4. BES. http://www.ttools.co.jp/product/eyes/BES/. (in Japanese)

5. EDEL-plus. http://www7a.biglobe.ne.jp/ EDEL-plus/. (in Japanese)

6. Tiger Software Suite, VIEWPLUS. http://www.viewplus.com/products/software/ braille-translator/

7. PostScript, Adobe Systems. https://www.adobe.com/products/postscript.html 
Open Access This chapter is licensed under the terms of the Creative Commons Attribution 4.0 International License (http://creativecommons.org/licenses/by/4.0/), which permits use, sharing, adaptation, distribution and reproduction in any medium or format, as long as you give appropriate credit to the original author(s) and the source, provide a link to the Creative Commons license and indicate if changes were made.

The images or other third party material in this chapter are included in the chapter's Creative Commons license, unless indicated otherwise in a credit line to the material. If material is not included in the chapter's Creative Commons license and your intended use is not permitted by statutory regulation or exceeds the permitted use, you will need to obtain permission directly from the copyright holder.

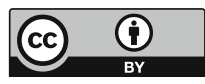

